\title{
Pediatric intramedullary schwannoma with syringomyelia: a case report and literature review
}

\author{
Keda Wang ${ }^{1,2,3}$, Jizong Zhao ${ }^{2,3^{*}}$, Yan Zhang ${ }^{2,3}$ and Yibing Su ${ }^{1}$
}

\begin{abstract}
Background: Intramedullary schwannomas without neurofibromatosis are exceedingly rare. They are rarer in children with only 8 cases reported so far. The association of intramedullary schwannomas with syringomyelia is also rare. Here, we present a case of intramedullary schwannoma with syringomyelia treated surgically in an 9-year-old boy.

Case presentation: We reviewed the clinical course of a 9-year-old boy, who presented with both lower extremity weakness of 6-month duration. Neurophysical examination revealed a decreased sensation below the T10 dermatome. Magnetic resonance imaging (MRI) showed an well-demarcated intramedullary lesion located at the level of T8 vertebra with isointensity on T2WI and hypointensity on T1WI, which was homogeneous enhanced after gadolinium injection. There was associated syringomyelia extending from T7 down to the level of T10. A mild scoliotic deformity was also observed. The lesion was totally resected after an T7-T8 laminoplasty. Histopathological findings were consistent with schwannoma. Postoperative MRI did not reveal the presence of a residual tumor with syringomyelia reducted. By 2 weeks after treatment, the patient had experienced nearly complete recovery. Management with external bracing was performed on this patient for 3 months after surgery to prevent spinal deformity. However, mild spinal kyphosis occurred 5 months after surgery, and a progressive postoperative spinal kyphosis was observed during these 3 years of follow-up. Continued conservative management with observation was performed as there is no association with functional decline and impairment in health-related quality-of-life measures.

Conclusion: Although extremely rare and uncommonly associated with syringomyelia, schwannomas need to be considered in the preoperative diagnosis of solitary intramedullary tumors in children as total resection can be achieved improving surgical outcome; Pediatric patients should be monitored closely for the development of spinal deformity following resection of intramedullary schwannoma, particularly possessing preoperative scoliotic deformity and/or tumor-associated syringomyelia.
\end{abstract}

Keywords: Intramedullary tumor, Schwannoma, Syringomyelia, Spinal deformity, Pediatrics

\section{Background}

Schwannomas are the most common primary tumors of the spine, and are usually located intradurally extramedullary [1]. Intramedullary schwannomas account for $0.3 \%$ of intraspinal tumors and $1.1 \%$ of intraspinal schwannomas $[2,3]$. Because of the rarity of this tumor, only about 60 cases have been reported in the spinal

\footnotetext{
*Correspondence: wkd169978@126.com; zhaojz205@163.com

${ }^{2}$ Department of Neurosurgery, Beijing Tiantan Hospital, Capital Medical University, NO6, Tiantan Xili, Dongcheng District, Beijing 100050, China ${ }^{3}$ China National Clinical Research Center for Neurological Diseases, NO6, Tiantan Xili, Dongcheng District, Beijing 100050, China

Full list of author information is available at the end of the article
}

cord without neurofibromatosis and generally present in the fourth decade of life $[1,4,5]$. Pediatric intramedullary schwannoma without neurofibromatosis is extremely rare with only eight cases reported so far [6-13]. Since the risk involved in removal and the surgical strategy are different for intramedullary schwannomas and intramedullary astrocytomas, awareness of this possible diagnosis will help establish the optimum medical and surgical treatment and the prognosis [14]. In addition, the association of intramedullary schwannomas with syringomyelia can be found but are uncommon [8]. Here, we present a surgically treated case of pediatric intramedullary schwannoma with syringomyelia, which developed a

(c) The Author(s). 2018 Open Access This article is distributed under the terms of the Creative Commons Attribution 4.0 International License (http://creativecommons.org/licenses/by/4.0/), which permits unrestricted use, distribution, and 
progressive spinal kyphosis during these 3 years of postoperative follow-up.

\section{Case presentation}

A 9-year-old Han Chinese boy presented with both lower extremity weakness of 6-month duration. Neurophysical examination revealed weakness of the lower extremities (power grade $\mathrm{I} / \mathrm{V} \mathrm{V}$ ) and decreased sensation below the T10 dermatome with bilateral knee tendon hyperreflexia and Babinski sign positive. Magnetic resonance imaging (MRI) showed an well-demarcated intramedullary lesion located at the level of T8 vertebra with isointensity on T2WI (Fig. 1) and hypointensity on T1WI, which was homogeneous enhanced after gadolinium injection (Fig. 2). There was associated syringomyelia extending from $\mathrm{T} 7$ down to the level of T10. A right thoracolumbar scoliosis with a Cobb angle of $28^{\circ}$ was also observed (Fig. 3). The patient underwent a T7-8 laminectomy. Opening the dura mater revealed a well-demarcated, soft, greyish-red tumor (Fig. 4). The lesion was totally resected with the help of microsurgical techniques. T7-8 laminoplasty was performed to keep the integrity of spinal structural. Histopathological findings were consistent with fibrillary schwannoma. Postoperative MRI did not reveal the presence of a residual tumor with syringomyelia reduced. By 2 weeks after treatment, the patient had experienced nearly complete recovery. Management with external bracing was performed on this patient for 3 months after surgery to prevent spinal deformity. However, a thoracic kyphotic deformity with a Cobb angle of $30^{\circ}$ occurred 5 months after surgery (Fig. 5), and a progressive postoperative spinal kyphosis with a Cobb angle of $60^{\circ}$ was observed 3 years after surgery (Fig. 6). Continued conservative management with observation was performed as there is no association with functional decline and impairment in health-related quality-of-life measures.

\section{Discussion and conclusions}

Intramedullary schwannomas are very rare, and only about 60 cases have been reported without neurofibromatosis and generally present in the fourth decade of life $[1,4,5]$. Intramedullary schwannomas is known to occur more in males than in females, and were more commonly seen in the cervical cord $[15,16]$. The cause of intramedullary schwannomas is still unknown. There are several hypotheses on the origin of intramedullary schwannomas [17-21]. To date, only eight pediatric cases of intramedullary schwannoma without neurofibromatosis have been reported in the PubMed published English literature [6-13], not including an extensive thoracolumbar congenital intramedullary schwannoma [22]. In the present case, intramedullary schwannoma occurred at the age of nine. By reviewing nine pediatric cases

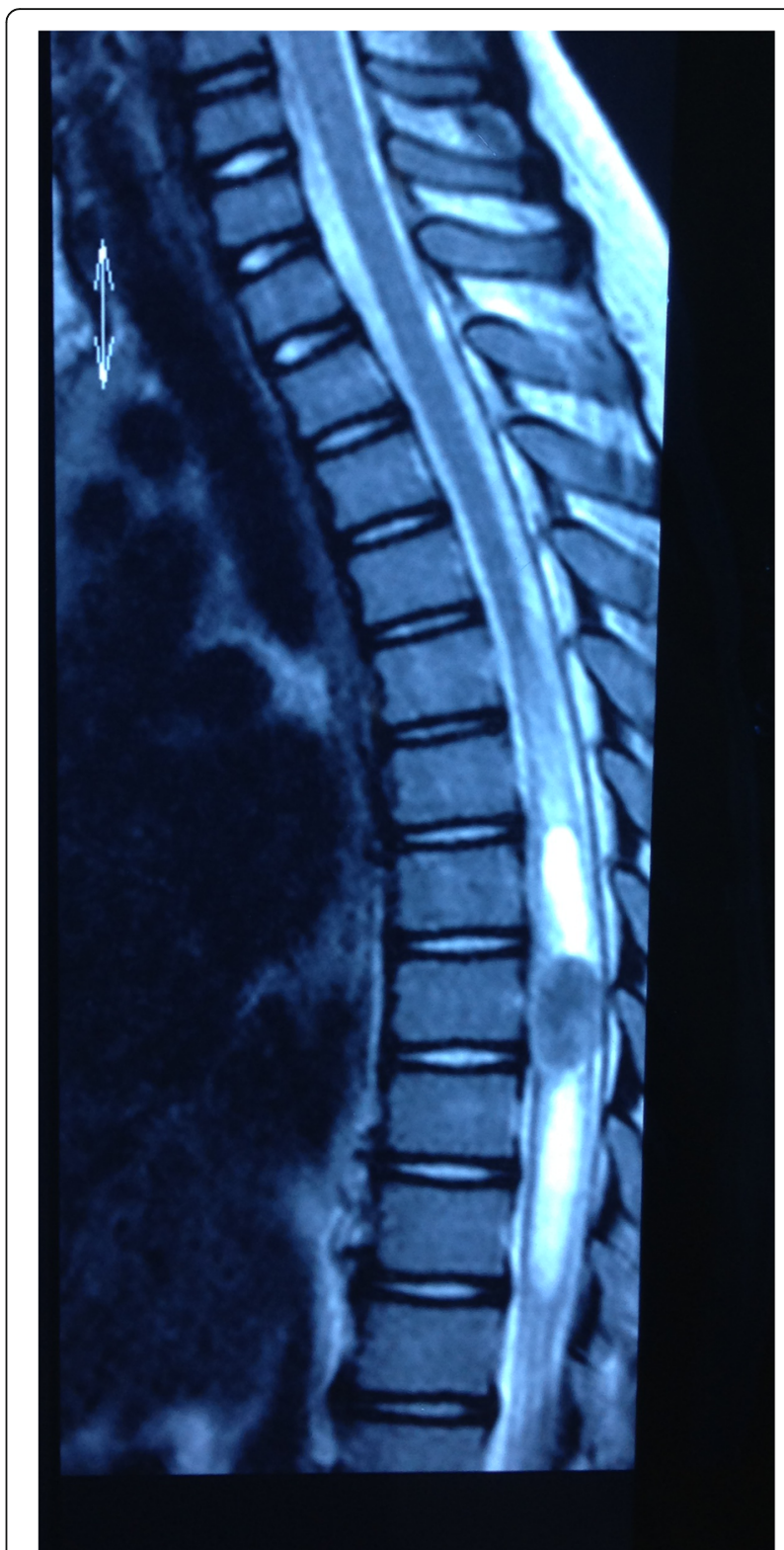

Fig. 1 Magnetic resonance imaging (MRI) sagital T2WI showed an well-demarcated intramedullary lesion associated with syringomyelia

including the present one, age ranged from 8 to 15 years, with a median age of 10 years. The predominance of male (male: female $=7: 2$ ) is consistent with the previous literature. The involved vertebral levels of pediatric intramedullary schwannomas are cervical $(4 / 9,44.4 \%)$, thoracic $(4 / 9,44.4 \%)$ and cervicothoracic $(1 / 9,11.1 \%)$ respectively.

MRI is the modality of choice for diagnosing spinal cord tumors. Many imaging studies have been conducted to characterize intramedullary schwannoma. Intramedullary schwannomas are usually isointense or hypointense on T1-weighted images and hyperintense on T2-weighted images [1, 5-10, 15]. Hypointense areas on T2-weighted 


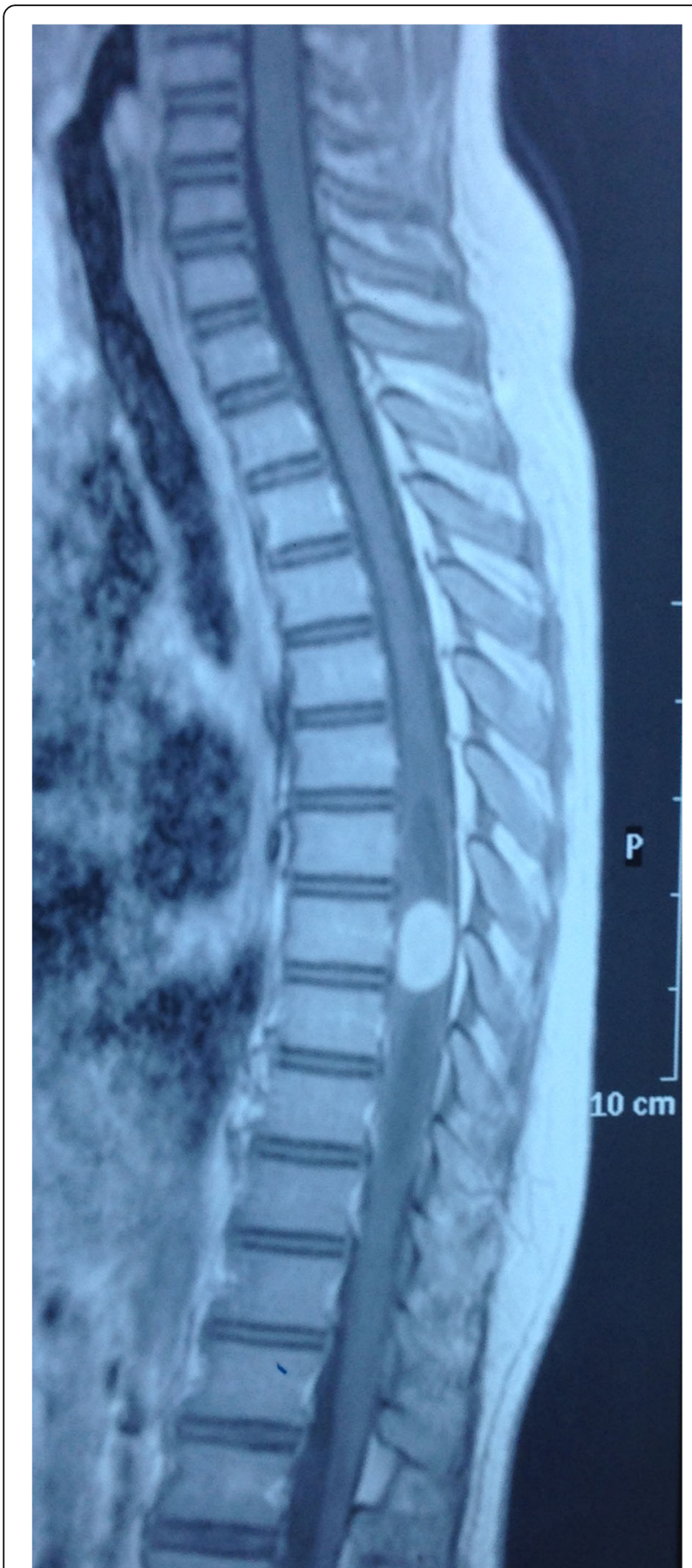

Fig. 2 Magnetic resonance imaging (MRI) sagittal T1 with contrast showed an well-demarcated intramedullary lesion associated with syringomyelia

images add evidence to diagnose intramedullary schwannomas $[1,15]$. A well-demarcated tumor with these features, and showing obvious enhancement, with absence of syringomyelia, should raise the possibility of an intramedullary schwannoma [15]. Generally, the absence of syringomyelia is one of characteristic MRI finding of intramedullary

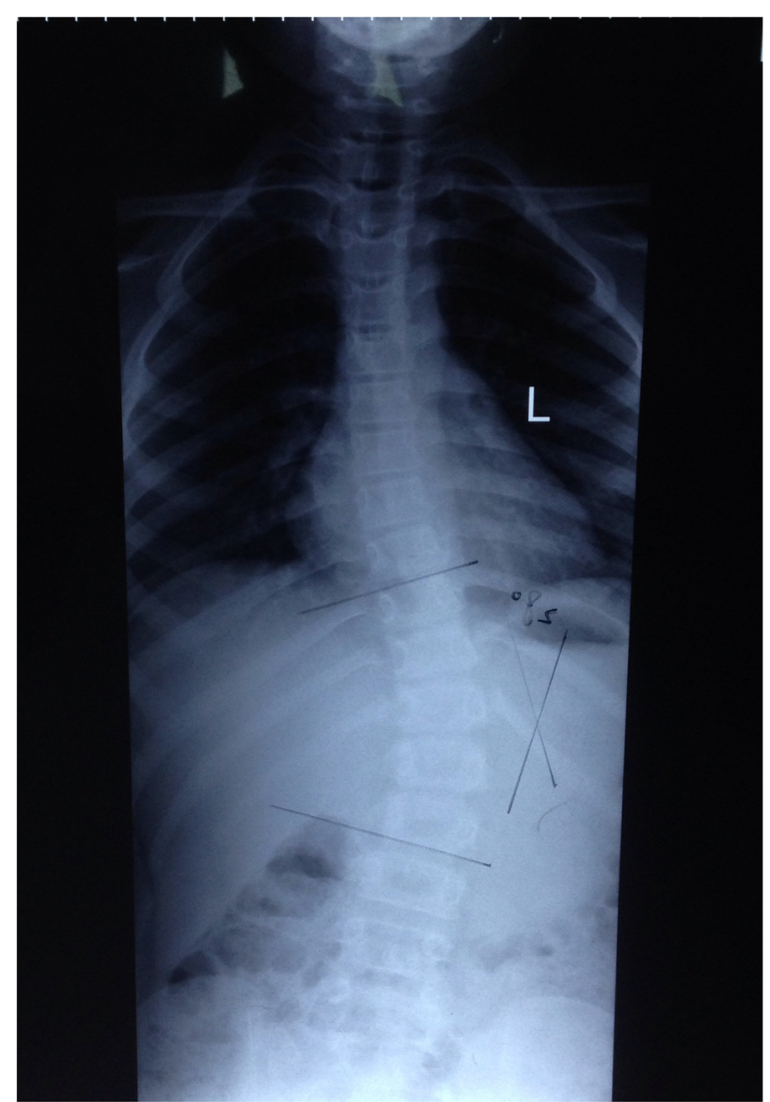

Fig. 3 A preoperative scoliotic deformity was also observed

schwannomas $[2-7,9,15]$. However, the association of syringomyelia were also reported in some cases of intramedullary schwannoma [1, 6, 8, 10]. Yang et al. [1] reported 9 of 20 cases of intramedullary schwannoma had syringomyelia. In our case, there was associated syringomyelia extending from T7 down to the level of T10. By reviewing 9 pediatric cases including the present one, 4 cases were found associated syringomyelia $[6,8,10]$. We speculate that the

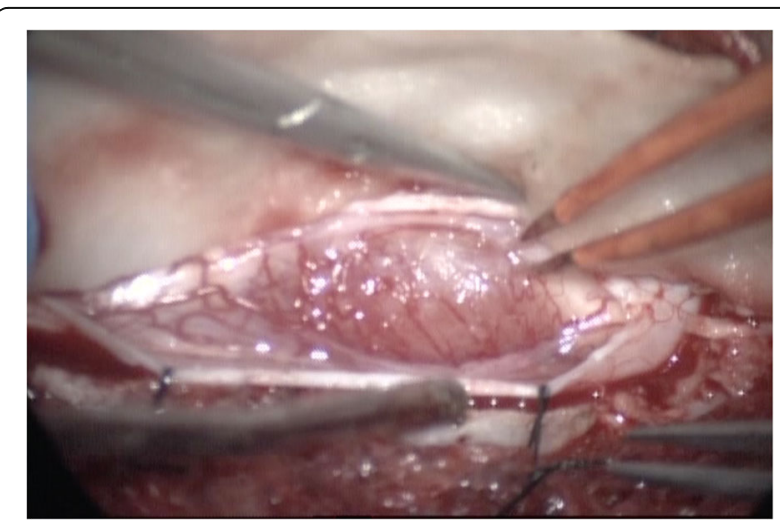

Fig. 4 A well-demarcated, soft, greyish-red tumor was observed during operation 


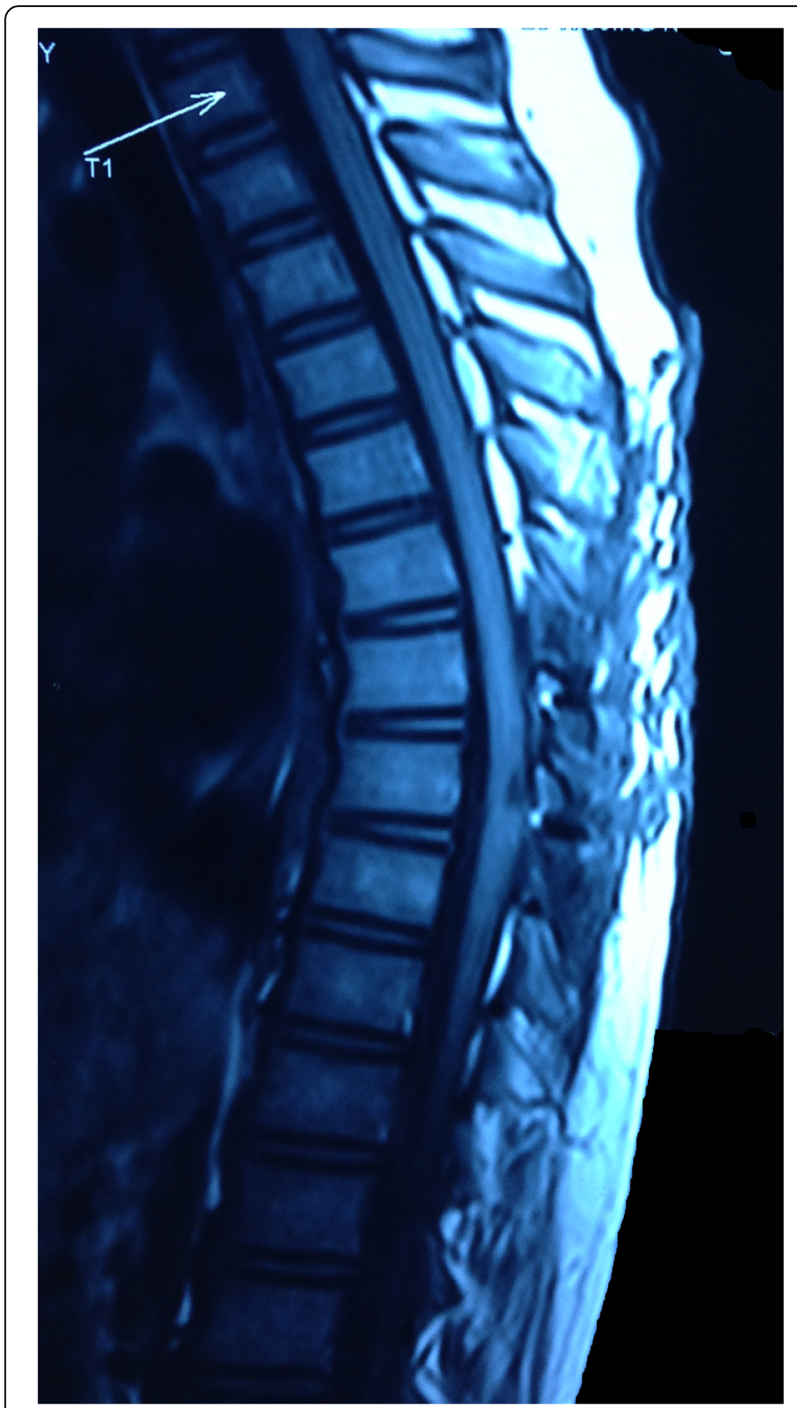

Fig. $5 \mathrm{MRI}$ revealed a mild spinal kyphosis 5 months after surgery

syringomyelia was caused by tumor which may obstruct the circulation of cerebrospinal fluid in the central canal. Therefore, we believe that the absence of syringomyelia is common but not specific. Associated syringomyelia can be found but uncommon. The differential diagnosis includes all other type of intramedullary lesions, such as astrocytoma, ependymoma, and hemangioblastoma [4, 15]. However, these lesions have other characteristic imaging features. Most astrocytomas commonly have ill-defined tumor margins with mild enhancement even no enhancement; Intramedullary ependymomas are usually located in the central part of the spinal cord and often associated with syringomyelia; Flow void, hemorrhage, and a typically bright enhancing pattern is evidence in favor of a hemangioblastoma. In addition, these lesions are usually associated with peritumoral edema and tumor cysts. Although Yang et al. [1] have

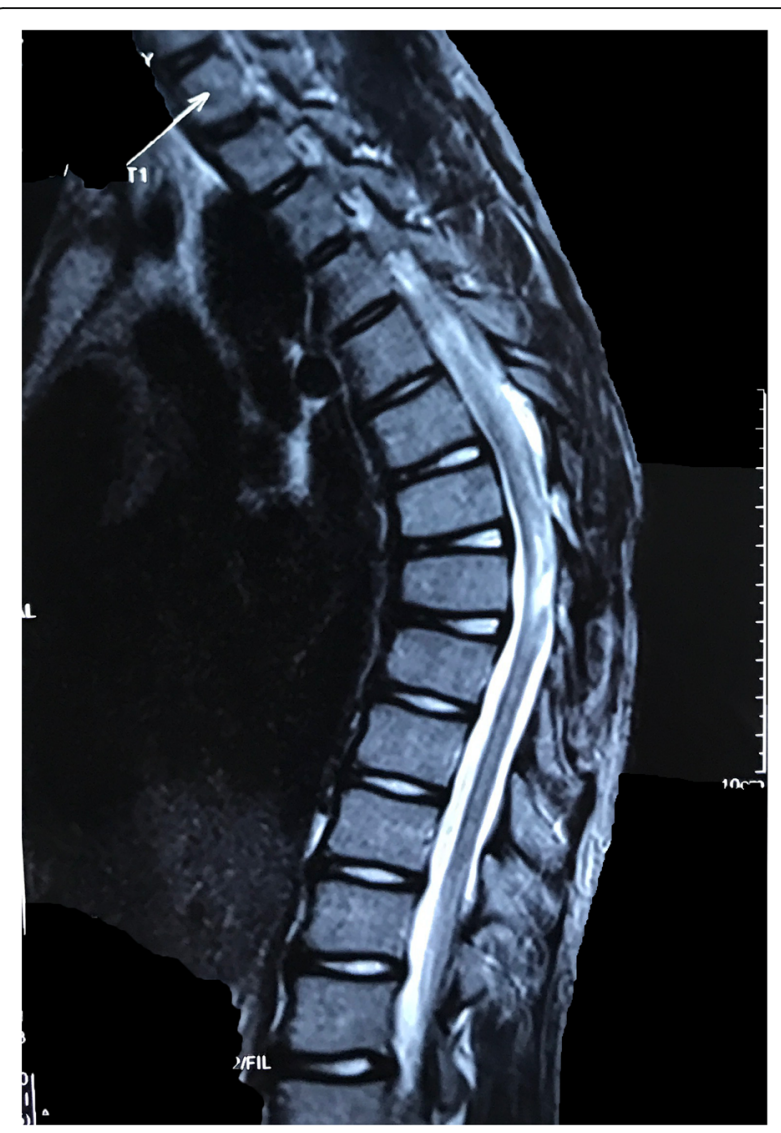

Fig. 6 Postoperative MRI did not reveal the presence of a residual tumor and a progressive spinal kyphosis was observed 3 years after surgery

reported that peritumoral edema is uncommon, Gao et al. [15] found most intramedullary schwannomas had different degrees of peritumoral edema. On the other hand, tumor cyst are not uncommon in intramedullary schwannomas. Yang et al. [1] found 55\% (11/20) of intramedullary schwannomas with associated cyst formation. Therefore, there is no uniformity on imaging features of intramedullary schwannomas, it may still be difficult to identify based only on MRI.

Total surgical resection should be attempted because of the benign nature of schwannomas $[1,4]$. However, total resection may be difficult in some cases [6, 8]. Yang et al. [1] reported 20 cases of intramedullary schwannoma, among of which 16 cases achieved gross total resection (GTR) and 4 cases subtotal resection (STR), and thought a good clinical outcome after GTR or STR can be expectd. Lee et al. [4] reported a $80 \%(8 / 10)$ GTR rate of intramedullary schwannomas. By reviewing reported 8 pediatric intramedullary schwannomas, the GTR rate is 50\% (4/8) [7, 9-11]. In our case, the tumor achieved GTR as there is a well-demarcated dissection plane to the surrounding neural tissue. Yang et al. [1] observed syrinx reduction in $77.8 \%$ (7/9) of intramedullary schwannoma patients with 
syringomyelia after the surgery and none with syrinx extension. However, Kim et al. [8] reported a case of pediatric intramedullary schwannoma associated with syringomyelia, and described an extension of syringomyelia after the tumor subtotally resected. In our case, syrinx reduction was observed after GTR of the tumor. Therefore, in view of the syringomyelia secondary to the intramedullary schwannoma, we don't need to drain the syrinx additionally, because it may collapse after tumor removal. The long-term outcomes of intramedullary schwannomas remains unclear as it's rarity. Yang et al. [1] reported 20 operated cases and concluded that a good prognosis can be achieved after GTR or STR. By reviewing reported pediatric cases, only one case experienced aggravation 9 months after subtotal resection of the tumor because of the extension of the syrinx [8]. In the present case there was no recurrence or clinical deterioration after 3 years follow-up. However, a progressive postoperative spinal kyphosis was observed during these 3 years of follow-up. Currently, there are some studies on postoperative spinal deformity after resection of intramedullary spinal cord tumors (IMSCTs). Pediatric patients with preoperative kyphoscoliosis or tumor-associated syrinx or surgery spanning more than 4 levels should be monitored for development of spinal deformity [23, 24]. In our case, progressive postoperative spinal kyphosis may be related to these risk factors.

Although extremely rare and uncommonly associated with syringomyelia, schwannomas need to be considered in the preoperative diagnosis of solitary intramedullary tumors in children as total resection can be achieved improving surgical outcome; Pediatric patients should be monitored closely for the development of spinal deformity following resection of intramedullary schwannoma, particularly possessing preoperative scoliotic deformity and/or tumor-associated syringomyelia.

\section{Abbreviations}

GTR: Gross total resection; IMSCTs: Intramedullary spinal cord tumors; MRI: Magnetic resonance imaging; STR: Subtotal resection; T2Wl: T2weighted images; TIWI: T1-weighted images

\section{Acknowledgements}

None.

\section{Funding}

The ministry of Science and Technology of China (No.2015BAl12B04), and Beijing Jishuitan Hospital Nova Program (NO. XKXX201618). The funding plays the role in the design of the study.

\section{Availability of data and materials}

All data have been presented within the manuscript.

\section{Authors' contributions}

KDW examined the patient, performed the neuropathologic analysis and drafted the manuscript; YZ participated in the conception and design of the case report and gave input into the discussion of neuroradiological findings; YBS performed the surgery and wrote the neurosurgical part of the case report; JZZ critically revised the manuscript and gave the final approval of the version to be published. All authors read and approved the final manuscript.
Ethics approval and consent to participate

The study was approved by the ethical committee of Beijing Tiantan Hospital, Capital Medical University.

\section{Consent for publication}

Parents of the patient provide written informed consent for the publication of the personal data and accompanying images presented in this manuscript.

\section{Competing interests}

The authors declare that they have no competing interests.

\section{Publisher's Note}

Springer Nature remains neutral with regard to jurisdictional claims in published maps and institutional affiliations.

\section{Author details}

${ }^{1}$ Department of Neurosurgery, Beijing Jishuitan Hospital, NO31, Xinjiekou East Street, Xicheng District, Beijing 100035, China. 'Department of Neurosurgery, Beijing Tiantan Hospital, Capital Medical University, NO6, Tiantan Xili, Dongcheng District, Beijing 100050, China. ${ }^{3}$ China National Clinical Research Center for Neurological Diseases, NO6, Tiantan Xili, Dongcheng District, Beijing 100050, China.

Received: 27 February 2018 Accepted: 12 November 2018 Published online: 28 November 2018

\section{References}

1. Yang T, Wu L, Deng XF, Yang CL. Clinical features and surgical outcomes of intramedullary schwannomas. Acta Neurochir. 2014;156:1789-97.

2. Colosimo C, Cerase A, Denaro L, Maira G, Greco R. Magnetic resonance imaging of intramedullary spinal cord schwannomas. Report of two cases and review of the literature. J Neurosurg. 2003;99(1 Supple):114-7.

3. Kodama Y, Terae S, Hida K, Chu BC, Kaneko K, Miyasaka K. Intramedullary schwannoma of the spinal cord: report of two cases. Neuroradiology. 2001; 43(7):567-71.

4. Lee SE, Chung CK, Kim HJ. Intramedullary schwannomas: long-term outcomes of ten operated case. J Neuro-Oncol. 2013;113:75-81.

5. Ho T, Tai KS, Fan YW, Leong LL. Intramedullary spinal schwannoma: case report and review of preoperative magnetic resonance imaging features. Asian J Surg. 2006;29:306-8.

6. Jagannatha AT, Joshi KC, Srikantha U, Varma RG, Mahadevan A. Pediatric calcified intramedullary schwannoma at conus: a common tumor in a vicarious location. J Pediatr Neurosci. 2016;11(4):319-21.

7. Eljebbouri B, Gazzaz M, Akhaddar A, Elmostarchid B, Boucetta M. Pediatric intramedullary schwannoma without neurofibromatosis: case report. Acta Medica Iranica. 2013;51(10):727-9.

8. Kim NR, Suh YL, Shin HJ. Thoracic pediatric intramedullary schwannoma: report of a case. Pediatr Neurosurg. 2009;45(5):396-401.

9. Mukerji G, Sherekar S, Yadav YR, Chandrakar SK, Raina VK. Pediatric intramedullary schwannoma without neurofibromatosis. Neurol India. 2007; 55(1):54-6.

10. Binatli $O$, Ersahin $Y$, Korkmaz O, Bayol U. Intramedullary schwannoma of the spinal cord. A case report and review of the literature. J Neurosurg Sci. 1999:43:163-8.

11. Sharma SC, Ray RC, Banerjee AK. Intramedullary spinal schwannoma. Indian Pediatr. 1989;26:290-2.

12. Gorman PH, Rigamonti D, Joslyn JN. Intramedullary and extramedullary schwannoma of the cervical spinal cord-case report. Surg Neurol. 1989;32: 459-62.

13. Rasmussen TB, Kernoha JW, Adson AW. Pathologic classification, with surgical consideration of intraspinal tumors. Ann Surg. 1940;3:513-30.

14. Wu L, Yao N, Chen DX, Deng XF, Xu YL. Preoperative diagnosis of intramedullary spinal schwannomas. Neurol Med Chir (Tokyo)2011;51:630-634.

15. Gao L, Sun B, Han F, Jin YY, Zhang JW. Magnetic resonance imaging features of intramedullary schwannomas. J Comput Assist Tomogr. 2017;41: 137-40.

16. Nicácio JM, Rodrigues JC, Galles MH, Faquini IV, de Brito Pereira CA, Ganau M. Cervical intramedullary schwannoma: a case report and review of the literature. Rare Tumors. 2009;1:e44.

17. Ramamurthi B, Anguli VC, Iyer CG. Acase of intramedullary neurinoma. J Neurol Neurosurg Psychiatry. 1958;21:92-4. 
18. Hughes JT, Brownell B. Aberrant nerve fibers within the spinal cord. J Neurol Neurosurg Psychiatry. 1963;26:528-34.

19. Riggs HE, Clary WU. A case of intramedullary sheath cell tumor of the spinal cord; consideration of vascular nerves as a source of origin. J Neuropathol Exp Neurol. 1957;16:332-6.

20. Feigin I, Ogata J. Schwann cells and peripheral myelin within human central nervous tissue: the mesenchymal character of Schwann cells. J Neurolpathol Exp Neurol. 1971;30:603-12.

21. O'Brien DF, Farrell M, Fraher JP, Bolger C. Schwann cell invasion of the conus medullaris: case report. Eur Spine J. 2003;12:328-31.

22. Lyle CA, Malicki D, Senac MO, Levy ML, Crawford JR. Congenital giant intramedullary spinal cord schwannoma. Neurology. 2010;75(19):1752.

23. Yao KC, McGirt MJ, Chaichana KL, Constantini S, Jallo Gl. Risk factors for progressive spinal deformity following resection of intramedullary spinal cord tumors in children: an analysis of 161 consecutive cases. J Neurosurg. 2007;107(6 Suppl):463-8.

24. Ahmed R, Menezes AH, Awe OO, Mahaney KB, Torner JC, Weinstein SL. Long-term incidence and risk factors for development of spinal deformity following resection of pediatric intramedullary spinal cord tumors. J Neurosurg Pediatr. 2014;13(6):613-21.

Ready to submit your research? Choose BMC and benefit from:

- fast, convenient online submission

- thorough peer review by experienced researchers in your field

- rapid publication on acceptance

- support for research data, including large and complex data types

- gold Open Access which fosters wider collaboration and increased citations

- maximum visibility for your research: over $100 \mathrm{M}$ website views per year

At BMC, research is always in progress.

Learn more biomedcentral.com/submissions 